\title{
Autonomous Flight Control System for Longitudinal Motion of a Helicopter
}

\author{
Atsushi Fujimori \\ University of Yamanashi \\ Japan
}

\section{Introduction}

Recently, unmanned aerial vehicles (UAVs) have been developed for the purposes of scientific observations, detecting disasters, surveillance of traffic and army objectives (Wilson, 2007; Langelaan \& Rock, 2005; Cho et al., 2005). This paper presents an autonomous flight control design to give insights for developing helicopter-type UAVs.

A Helicopter is generally an unstable aircraft. Once it is stalled, it is not easy to recover its attitude. A control system is therefore needed to keep the vehicle stable during flight (Bramwell, 1976; Padfield, 1996; Johnson \& Kannan, 2005). This paper presents a flight control design for the longitudinal motion of helicopter to establish autopilot techniques of helicopters. The flight mission considered in this paper is that a helicopter hovers at a start position, moves to a goal position with keeping a specified cruise velocity and hovers again at the goal. The characteristics of the linearized equation of the helicopter is changed during this flight mission because the trim values of the equation are widely varied. Gain scheduling (GS) is one of candidates to stabilize the vehicle for the entire flight region. In this paper, a flight control system is designed as follows. The flight control system is constructed as a double loop control system (Fujimori et al., 1999; Fujimori et al., 2002) which consists of an inner-loop controller and an outer-loop controller. The former is needed for stabilizing the controlled plant, while the latter is used for tracking the reference which is given to accomplish the flight mission. To design the inner-loop controller, the longitudinal motion of a helicopter is first modeled by a linear interpolative polytopic model whose varying parameter is the flight velocity. A GS state feedback law is then designed by linear matrix inequality (LMI) (Boyd et al., 1994; Fujimori et al., 2007) so as to stabilize the polytopic model for the entire flight region. On the other hand, the outer-loop controller is designed by taking into consideration the steady-state of the controlled variable.

The rest of this paper is organized as follows. Section 2 shows equations of the longitudinal motion of helicopter. Section 3 gives a flight mission and shows a double loop control system adopted in this paper. The details of the controller designs are presented in Section 4. Section 5 shows computer simulation in Matlab/Simulink to evaluate the proposed flight control system. Concluding remarks are given in Section 6. 


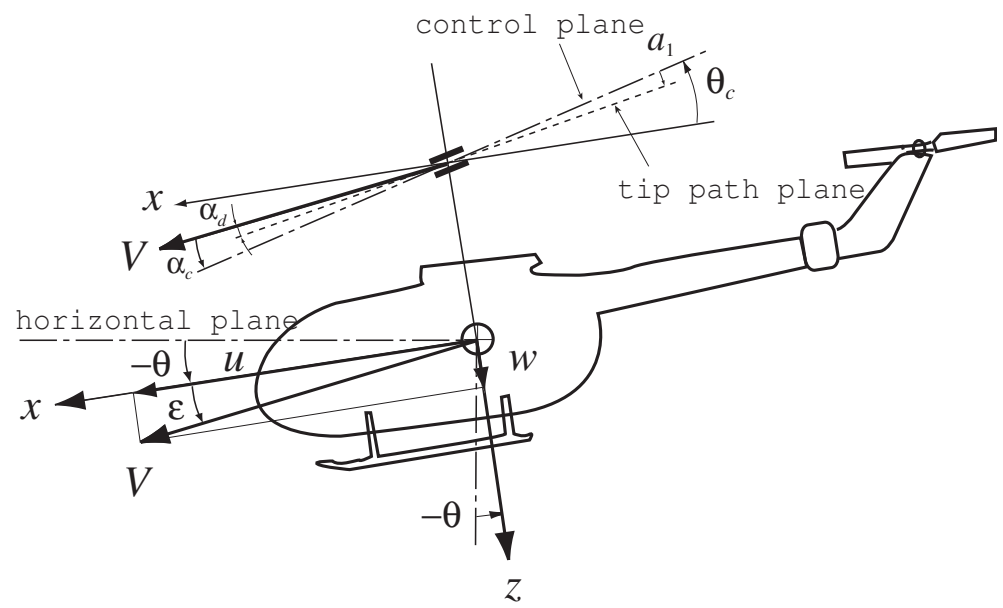

Fig. 1. Helicopter in forward flight

\section{Equation of longitudinal motion of helicopter}

Figure 1 shows a helicopter considered in this paper. The angular velocity of the main rotor is $\Omega$. The main rotor produces the thrust $T$ which is needed for not only lifting the vehicle against the gravity but also moving transitionally and rotationally. It depends on the tilting angle of the control plane.

$(x, y, z)$ represent the body-fixed-axes whose origin is located at the center of gravity of the vehicle. The forward velocity is $V$ whose $x$ - and $z$-axes elements are $u$ and $w$, respectively. The longitudinal motion of helicopter consists of the transitional motion with respect to $x$ and $z$-axes and the rotational motion around $y$-axis; that is, the pitch angle denoted as $\theta$ and its derivative $q(=\dot{\theta})$. It is represented as the following equations (Bramwell, 1976; Padfield, 1996):

$$
\begin{gathered}
m(\dot{u}+q w)=X-m g \sin \theta \\
m(\dot{w}-q u)=Z+m g \cos \theta \\
I_{y y} \dot{q}=M
\end{gathered}
$$

where $m$ and $I_{y y}$ are respectively the mass and the moment of inertia of the vehicle. $g$ is the gravity acceleration. The external forces $X, Z$ and the moment $M$ are given by

$$
\begin{gathered}
X=T \sin \left(\theta_{c}-a_{1}\right)-D \cos \varepsilon \\
Z=-T \cos \left(\theta_{c}-a_{1}\right)-D \sin \varepsilon \\
M=-T h_{R} \sin \left(\theta_{c}-a_{1}\right)
\end{gathered}
$$

where $\varepsilon$ is defined as $\varepsilon \tan . \theta_{\mathcal{c}}$ is the cyclic pitch angle which is one of the control inputs for the longitudinal motion of the helicopter. $a_{1}$ is the angle between the control plane and the tip path plane. $h_{R}$ is the distance of the hub from the center of gravity. $D$ is the drag of the vehicle and is given by

$$
D=\frac{1}{2} \rho V^{2} S C_{D}
$$


where $\rho$ is the atmospheric density, $S$ the representative area and $C_{D}$ the drag coefficient. The thrust $T$ can be calculated by integrating the lift over the whole blade. This results in the following expression for the thrust coefficient:

$$
C_{T} \triangleq \frac{T}{\rho(\Omega R)^{2} \pi R^{2}}=\frac{N c}{4 \pi R} C_{l \alpha}\left\{\left(\frac{2}{3}+\mu^{2}\right) \theta_{0}-\lambda_{c}-\lambda_{i}\right\}
$$

where

$$
\begin{aligned}
\mu \triangleq \frac{V}{\Omega R} \cos \alpha_{c}, \quad \lambda_{c} \triangleq \frac{V}{\Omega R} \sin \alpha_{c}, \quad \lambda_{i} \triangleq \frac{v_{i}}{\Omega R} \\
\alpha_{c} \triangleq \theta_{c}-\varepsilon
\end{aligned}
$$

$R$ is the radius of the rotor blades, $c$ the chord length, $N$ the number of the blades and $C_{l \alpha}$ the lift slope of the blades. $v_{i}$ is the induced velocity through the rotor. $\theta_{0}$ is the collective pitch angle which is another control input. According to Van Hoydonck (2003), the dimensionless induced velocity $\lambda_{i}$ through the rotor is approximated by

$$
\tau \dot{\lambda}_{i}=C_{T}-C_{T_{G l}}
$$

where $C_{T_{G l}}$ is the thrust coefficient which is given by Glauert's hypotheses. $\tau$ is a time constant of $\lambda_{i}$.

Summarizing the above equations, define the state and the input vectors as

$$
x_{p} \triangleq\left[\begin{array}{lllll}
u & w & q & \theta & \lambda_{i}
\end{array}\right]^{T} \in \Re^{5}, \quad u_{p} \triangleq\left[\begin{array}{ll}
\theta_{0} & \theta_{c}
\end{array}\right]^{T} \in \Re^{2} .
$$

The equation of the longitudinal motion of the helicopter is then written as

$$
\dot{x}_{p}=f_{p}\left(x_{p}, u_{p}\right) .
$$

Equation (13) is referred as the nonlinear plant $P_{n l}$ hereafter.

Letting $x_{e}$ and $h_{e}$ be horizontal and the vertical positions of the helicopter from the start, they are given by

$$
\begin{aligned}
& \dot{x}_{e}=u \cos \theta+w \sin \theta \\
& \dot{h}_{e}=u \sin \theta-w \cos \theta .
\end{aligned}
$$

Defining $\xi_{p}$ as $\xi_{p} \triangleq\left[\begin{array}{ll}x_{e} & h_{e}\end{array}\right]^{T}$, they are compactly given as

$$
\dot{\xi}_{p}=g_{p}\left(x_{p}\right) .
$$

In this paper, numerical values of the Eurocopter Deutschland Bo105 (Padfield, 1996) were used in simulation. They are listed in Table 1. Since this paper considers hovering and forward flight, the trim condition is given in level flight. Letting $\bar{x}_{p}$ and $\bar{u}_{p}$ be the state and the input in trim, respectively, $f\left(\bar{x}_{p}, \bar{u}_{p}\right)=0$ holds. Figure 2 shows variations of $\bar{x}_{p}$ and $\bar{u}_{p}$ with respect to the flight velocity $V$. It is seen that all trim values are changed in the range of $V \in[0,60]$ $[\mathrm{m} / \mathrm{s}]$. 

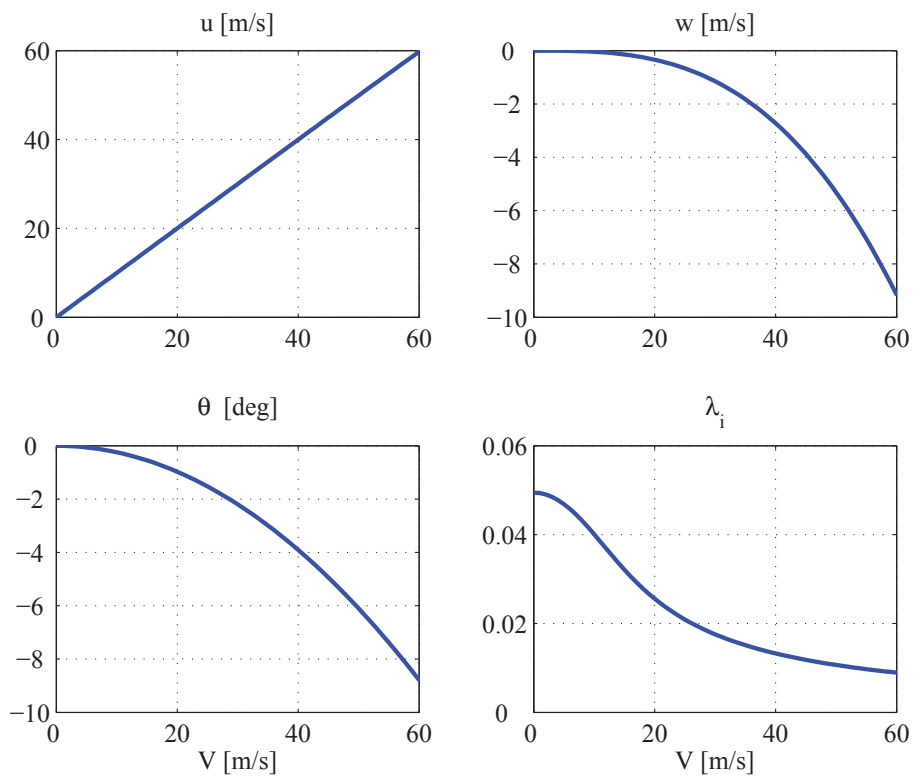

(a) States in trim $\bar{x}_{p}$
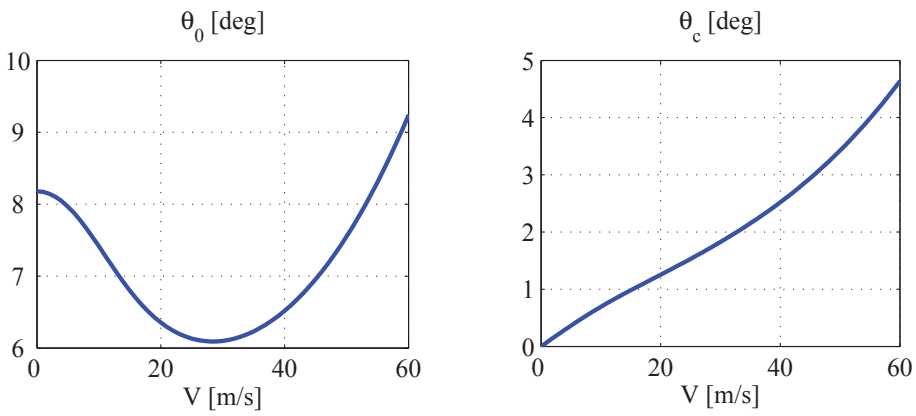

(b) Inputs in trim $\bar{u}_{p}$

Fig. 2. Trim values with respect to forward velocity $V$ 


\begin{tabular}{ccc}
\hline parameter & value & unit \\
\hline$C_{l \alpha}$ & 6.113 & {$[1 / \mathrm{rad}]$} \\
$c$ & 0.27 & {$[\mathrm{~m}]$} \\
$m$ & 2200 & {$[\mathrm{~kg}]$} \\
$I_{b l}$ & 231.7 & {$\left[\mathrm{kgm}^{2}\right]$} \\
$I_{y y}$ & 4973.0 & {$\left[\mathrm{kgm}^{2}\right]$} \\
$R$ & 4.91 & {$[\mathrm{~m}]$} \\
$\Omega$ & 44.4 & {$[\mathrm{rad} / \mathrm{s}]$} \\
$N$ & 4 & {$[-]$} \\
$C_{D} S$ & 1.5 & {$\left[\mathrm{~m}^{2}\right]$} \\
$h_{R}$ & 1.48 & {$[\mathrm{~m}]$} \\
\hline
\end{tabular}

Table 1. Parameters of Bo105 (Padfield, 1996)

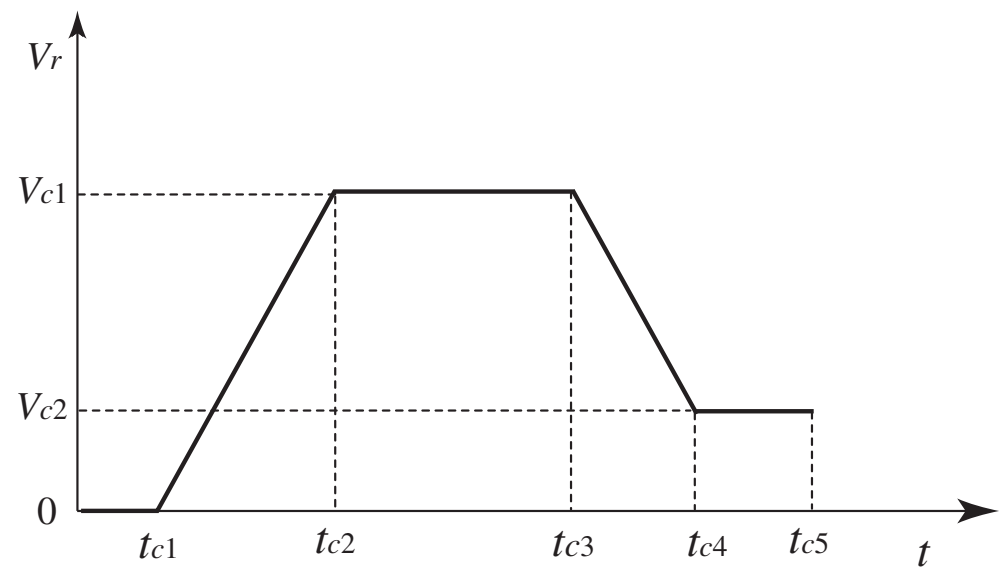

Fig. 3. Flight velocity profile $V_{r}$

\section{Construction of flight control system}

Let the start position be the origin of the coordinates $\left(x_{e}, h_{e}\right)$. A flight mission considered in this paper is to navigate the helicopter from the start $(0,0)$ to the goal, denoted as $\left(x_{r}, h_{r}\right)$, with keeping its attitude stable. To design a control system, the followings are assumed to be satisfied:

(i) The motion in $y$-axis direction is not taken into account.

(ii) $x_{p}$ is measurable.

(iii) The trim values $\bar{x}_{p}$ and $\bar{u}_{p}$ are known in advance.

To realize the flight mission, this paper constructs a tracking control system whose controlled variable is the flight velocity. The flight region is divided into six phases with respect to the flight velocity as shown in Fig. 3. They are referred as follows. 


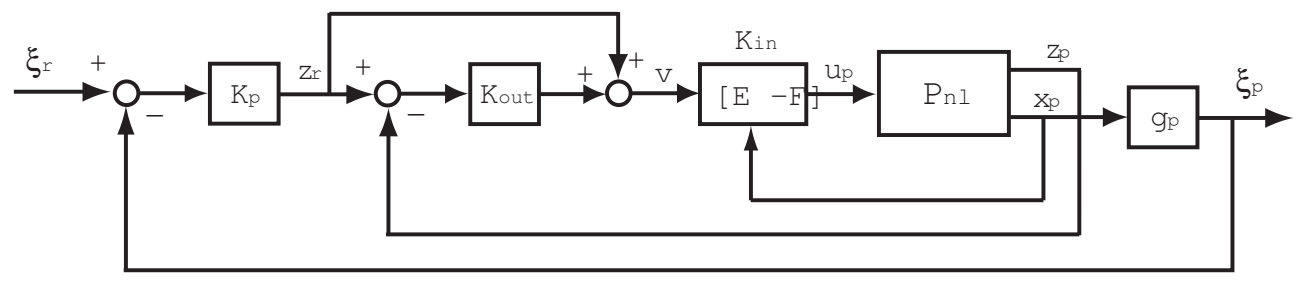

Fig. 4. Flight control system

$$
\begin{aligned}
& 0 \leq t<t_{c 1}: \text { initial hovering phase } \\
& t_{c 1} \leq t<t_{c 2}: \text { acceleration phase } \\
& t_{c 2} \leq t<t_{c 3}: \text { cruise phase } \\
& t_{c 3} \leq t<t_{c 4}: \text { deceleration phase } \\
& t_{c 4} \leq t<t_{c 5}: \text { low speed phase } \\
& t_{c 5} \leq t: \quad \text { approach phase }
\end{aligned}
$$

From the initial hovering phase to the low speed phase, the reference of the flight velocity is given by $V_{r}$ shown in Fig. 3. In this paper, the total time of the flight is not cared. But the integrated value of $V_{r}$ for $t \in\left[0, t_{c 5}\right]$ must be less than $x_{r}$ not to overtake the goal before the approach phase. In the approach phase, the reference is generated to meet the position of the helicopter $\xi_{p}=\left[\begin{array}{ll}x_{e} & h_{e}\end{array}\right]^{T}$ with the goal $\xi_{r}=\left[\begin{array}{ll}x_{r} & h_{r}\end{array}\right]^{T}$.

Taking into consideration the above, a double loop control system (Fujimori et al., 1999; Fujimori et al., 2002) is used as a flight control system in this paper. It is shown in Fig. 4. $P_{n l}$ represents the nonlinear helicopter dynamics given by Eq. (13), $K_{i n}$ is the inner-loop controller, $K_{\text {out }}$ is the outer-loop controller and $K_{p}$ is a gain. The controlled variable from the initial hovering phase to the low speed phase is given by $z_{p} \triangleq[u w]^{T}$ and its reference is given by $z_{r} \triangleq\left[u_{r} w_{r}\right]^{T}$. In the approach phase, another loop is added outside of $\left(z_{r}-z_{p}\right)$-loop, where $\xi_{p} \triangleq\left[x_{e} h_{e}\right]^{T}$ is the controlled variable and $\xi_{r} \triangleq\left[x_{r} h_{r}\right]^{T}$ is its reference.

$K_{\text {in }}$ consists of

$$
K_{\text {in }}=[E-F]
$$

where $E$ is a feedforward gain for tracking the reference, while $F$ is a feedback gain for stabilizing the plant. Since the trim values are widely varied as shown in Fig. 2, the characteristics of the linearized plant is also varied. Then, $F$ is designed by a GS technique in terms of LMI formulation (Boyd et al., 1994).

The reference $z_{r}$ from the initial hovering phase to the low speed phase is generated by the flight velocity profile shown in Fig. 3, and $z_{r}$ in the approach phase is derived from the positional error $\xi_{r}-\xi_{p}$. The switch of the reference is done at $t=t_{c 5}$.

\section{Design of control system}

\subsection{Linear interpolative polytopic model}

The objective of flight control in this paper is that the controlled variable is regulated to the specified trim condition. Linearized models along with the trim is therefore used for controller design. Letting $\bar{x}_{p}(V), \bar{u}_{p}(V)$ be respectively the state and the input in trim where the flight 
velocity is $V$, the perturbed state and the input are defined as

$$
\delta x_{p}(t) \triangleq x_{p}(t)-\bar{x}_{p}(V), \quad \delta u_{p}(t) \triangleq u_{p}(t)-\bar{u}_{p}(V)
$$

The linearized equation of Eq. (13) is then given as

$$
\delta \dot{x}_{p}(t)=A_{p}(V) \delta x_{p}(t)+B_{p}(V) \delta u_{p}(t)
$$

where

$$
A_{p}(V) \triangleq \frac{\partial f_{p}\left(\bar{x}_{p}, \bar{u}_{p}\right)}{\partial x_{p}^{T}}, \quad B_{p}(V) \triangleq \frac{\partial f_{p}\left(\bar{x}_{p}, \bar{u}_{p}\right)}{\partial u_{p}^{T}} .
$$

Although matrices $A_{p}$ and $B_{p}$ are functions with respect to $V$, it is hard to get their explicit representations because of complicated dependence of $V$ as described in Section 2. Then, $A_{p}$ and $B_{p}$ are approximated by interpolating multiple linearized models in the trim condition. For the range of the flight velocity $V \in\left[0, V_{u}\right], r$ points $\left\{V_{1}, \cdots, V_{r}\right\}$, called the operating points, are chosen as

$$
0 \leq V_{1}<\cdots<V_{r} \leq V_{u}
$$

The linearized model for $V=V_{i}$ is a local LTI model representing the plant near the $i$-th operating point. Linearly interpolating them, a global model over the entire range of the flight velocity is constructed as

$$
\left\{\begin{array}{l}
\delta \dot{x}_{p}(t)=A_{p}(V) \delta x_{p}(t)+B_{p}(V) \delta u_{p}(t) \\
z_{p}(t)=C_{p} \delta x_{p}(t)+\bar{z}_{p}(V)
\end{array}\right.
$$

where

$$
\begin{aligned}
& A_{p}(V)=\sum_{i=1}^{r} \mu_{i}(V) A_{p i}, \quad B_{p}(V)=\sum_{i=1}^{r} \mu_{i}(V) B_{p i},
\end{aligned}
$$

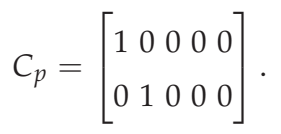

$\mu_{i}(V)$ satisfies the following relations.

$$
\begin{gathered}
0 \leq \mu_{i}(V) \leq 1 \quad(i=1, \cdots, r) \\
\sum_{i=1}^{r} \mu_{i}(V)=1
\end{gathered}
$$

Equation (22) with Eq. (23) is called the linear interpolative polytopic model in this paper.

4.2 Design of $K_{\text {in }}$ Under assumption (ii), consider a state feedback law

$$
\delta u_{p}(t)=-F(V) \delta x_{p}(t)+E(V) v(t)
$$


where $v$ is a feedforward input for tracking $z_{r}$ and is given by $v=z_{r}-\bar{z}_{p}$ when designing $K_{i n}$. The closed-loop system combining Eq. (26) with Eq. (22) is given by

$$
\begin{aligned}
& \left\{\begin{array}{l}
\delta \dot{x}_{p}(t)=A_{F}(V) \delta x_{p}(t)+B_{p}(V) E(V) v(t) \\
z_{p}(t)=C_{p}(V) \delta x_{p}(t)+D_{p}(V) E(V) v(t)+\bar{z}_{p}(V)
\end{array}\right. \\
& A_{F}(V) \triangleq A_{p}(V)-B_{p}(V) F(V) \text {. }
\end{aligned}
$$

The steady-state controlled variable is given by

$$
z_{p}(\infty)=-C_{p} A_{F}^{-1} B_{p} E v+\bar{z}_{p} .
$$

$v$ is then given so as to meet $z_{p}(\infty)$ with the reference $z_{r}$; that is, $z_{p}(\infty) \rightarrow z_{r}$. E is designed as

$$
E=-\left(C_{p} A_{F}^{-1} B_{p}\right)^{-1} \text {. }
$$

Next, $F(V)$ is designed so that the closed-loop system is stable over the entire flight range and $\mathcal{H}_{2}$ cost is globally suppressed (Fujimori et al., 2007). The controlled plant is newly given by

$$
\left\{\begin{array}{l}
\delta \dot{x}_{p}(t)=A_{p}(V) \delta x_{p}(t)+B_{p}(V) \delta u_{p}(t)+B_{1}(V) w_{1}(t) \\
z_{1}(t)=C_{1}(V) \delta x_{p}(t)+D_{1}(V) \delta u_{p}(t)
\end{array}\right.
$$

where $z_{1}$ and $w_{1}$ are respectively the input and the output variable for evaluating $\mathcal{H}_{2}$ cost. $B_{1}(V), C_{1}(V)$ and $D_{1}(V)$ are matrices corresponding to $z_{1}$ and $w_{1}$. Substituting Eq. (26) without $v$ into Eq. (30), the closed-loop system is

$$
\begin{gathered}
\left\{\begin{array}{c}
\delta \dot{x}_{p}(t)=A_{F}(V) \delta x_{p}(t)+B_{1}(V) w_{1}(t) \\
z_{1}(t)=C_{1 F}(V) \delta x_{p}(t)
\end{array}\right. \\
C_{1 F}(V) \triangleq C_{1}(V)-D_{1}(V) F(V) .
\end{gathered}
$$

In this paper, $F(V)$ is designed so as to minimize the integration of $\mathcal{H}_{2}$ cost over $V \in\left[0, V_{u}\right]$. That is, the objective is to find $F(V)$ such that (Boyd et al., 1994).

$$
\begin{gathered}
\inf _{F, P, W} \int_{0}^{V_{u}} \operatorname{tr} W(V) d V \text { subject to } \\
{\left[\begin{array}{cc}
P(V) & P(V) B_{1}(V) \\
(\star) & W(V)
\end{array}\right]>0} \\
{\left[\begin{array}{cc}
\operatorname{He}\left(P(V) A_{F}(V)\right)+\dot{V} \frac{d P}{d V} & (\star) \\
C_{1 F}(V) & -I_{q}
\end{array}\right]<0}
\end{gathered}
$$

$\mathrm{He}(A)$ is defined as $\mathrm{He}(A) \triangleq A+A^{T}$ where $(\star)$ means the transpose of the element located at the diagonal position. $P(V)>0$ is the parameter dependent Lyapunov variable. To derive finite number of inequalities from Eq. (32), the following procedures are performed. First define new variables $X(V) \triangleq P^{-1}(V)$ and $M(V) \triangleq F(V) X(V) . A_{p}(V)$ and $B_{p}(V)$ are given 
by the polytopic forms Eq. (23). $B_{1}(V), C_{1}(V), D_{1}(V), X(V), M(V)$ and $W(V)$ are also given by similar polytopic forms. The range of $\dot{V} \triangleq a_{V}$ is given as $a_{V} \in\left[a_{V}, \overline{a_{V}}\right]$. Furthermore, $d P / d V$ are approximated as

$$
\begin{gathered}
\frac{d P}{d V}=-X^{-1} \frac{d X}{d V} X^{-1} \\
\frac{d X}{d V} \simeq \frac{X_{i+1}-X_{i}}{V_{i+1}-V_{i}} \triangleq \frac{\Delta X_{i}}{\Delta V_{i}}
\end{gathered}
$$

Pre- and post-multiplying $\operatorname{diag}\{X, I\}$ to Eq. (32) and using the polytopic forms, the following LMIs are derived as a sufficient condition.

$$
\begin{gathered}
\inf _{M_{i}, X_{i}, W_{i}} \sum_{i=1}^{r-1} \operatorname{tr}\left(W_{i} \Delta V_{i}\right) \quad \text { subject to } \\
{\left[\begin{array}{cc}
X_{i} & B_{1 i} \\
(\star) & W_{i}
\end{array}\right]>0 \quad(i=1, \cdots, r),} \\
{\left[\begin{array}{cc}
\operatorname{He}\left(A_{p i} X_{i}-B_{p i} M_{i}\right)-a_{V} \frac{\Delta X_{i}}{\Delta V_{i}} & (\star) \\
C_{1 i} X_{i} D_{1 i} M_{i} & -I_{q}
\end{array}\right]<0,} \\
{\left[\begin{array}{cc}
\operatorname{He}\left(A_{p j} X_{j}-B_{p j} M_{j}\right)-a_{V} \frac{\Delta X_{i}}{\Delta V_{i}} & (\star) \\
C_{1 j} X_{j} D_{1 j} M_{j} & -I_{q}
\end{array}\right]<0,} \\
{\left[\begin{array}{cc}
\operatorname{He}\left(A_{p i} X_{j}-B_{p i} M_{j}\right. & (\star) \\
\left.+A_{p j} X_{i}-B_{p j} M_{i}\right)-2 a_{V} \frac{\Delta X_{i}}{\Delta V_{i}} & \\
C_{1 i} X_{j}-D_{1 i} M_{j} & -2 I_{q}
\end{array}\right]<0} \\
+C_{1 j} X_{i}-D_{1 j} M_{i}
\end{gathered}
$$

If $M_{i}, X_{i}$ and $W_{i}(i=1, \cdots, r)$ satisfying the above LMIs, $F(V)$ is given by

$$
F(V)=\left(\sum_{i=1}^{r} \mu_{i}(V) M_{i}\right)\left(\sum_{i=1}^{r} \mu_{i}(V) X_{i}\right)^{-1} .
$$

\subsection{Design of $K_{\text {out }}$}

Since $v$ in Eq. (26) is a feedforward input from the flight velocity reference, the tracking error will be occurred by model uncertainties and/or disturbances. Let us evaluate this in the LTI representation. Let $T_{z_{p} v}(s)$ be a transfer function from $v$ to $z_{p} . z_{p}$ converges to a constant $z_{r}$ if there are no model uncertainties in $T_{z_{p} v}(s)$ because $T_{z_{p} v}(0)=I$. If $T_{z_{p} v}(0)$ is varied as $T_{z_{p} v}(0)=$ $I+\Delta$ due to model uncertainties, we have the following steady-state error:

$$
e_{0} \triangleq z_{r}-z_{p}(\infty)=-\Delta z_{r}
$$




\begin{tabular}{lcc}
\hline Model & $V_{i}[\mathrm{~m} / \mathrm{s}]$ & GS-SF \\
\hline$P_{\text {poly }-1}$ & $\{0,50\}$ & $F_{g s-1}$ \\
$P_{\text {poly }-2}$ & $\{0,25,50\}$ & $F_{g s-2}$ \\
$P_{\text {poly-3 }}\{0,10,15,40,50\}$ & $F_{g s-3}$ \\
\hline
\end{tabular}

Table 2. Operating points of polytopic models

\begin{tabular}{ccc}
\hline Model & $V_{d}[\mathrm{~m} / \mathrm{s}]$ & Fixed-SF \\
\hline$P_{l t i-1}$ & 0 & $F_{f i x-1}$ \\
$P_{l t i-2}$ & 25 & $F_{f i x-2}$ \\
$P_{l t i-3}$ & 50 & $F_{f i x-3}$ \\
\hline
\end{tabular}

Table 3. Design points of LTI models

To reduce the error, a feedback from $z_{p}$; that is, an outer-loop is added as shown in Fig. 4 . The transfer function from $z_{r}$ to $z_{p}$ is given by

$$
T_{z_{p} z_{r}}(s)=\left(I+T_{z_{p} v}(s) K_{\text {out }}(s)\right)^{-1} T_{z_{p} v}(s)\left(I+K_{\text {out }}(s)\right)
$$

The steady-state error is then

$$
\begin{aligned}
e_{1} & \triangleq z_{r}-z_{p}(\infty)=z_{r}-\lim _{s \rightarrow 0} s T_{z_{p} z_{r}}(s) \frac{1}{s} z_{r} \\
& =-\left(I+T_{z_{p} v}(0) K_{\text {out }}(0)\right)^{-1} \Delta z_{r} .
\end{aligned}
$$

This means that the steady-state error $e_{1}$ with the outer-loop is reduced by $(I+$ $\left.T_{z_{p} v}(0) K_{\text {out }}(0)\right)^{-1}$. Summarizing the above, the design requirements of $K_{\text {out }}$ are given as follows:

(i) $K_{\text {out }}$ must stabilize $T_{z_{p} v}$.

(ii) The amplitude of $\left(I+T_{z_{p} v}(j \omega) K_{\text {out }}(j \omega)\right)^{-1}$ should be small in the low frequency region.

\section{Simulation}

To evaluate the proposed flight control system, a flight simulator was built on MATLAB/Simulink. For design and discussion hereafter, the notations about plant models are given as follows: $P_{l p v}(V)$ is a linear parameter varying (LPV) model obtained by linearizing $P_{n l} . P_{\text {poly }}(V)$ is the linear interpolative polytopic model given by Eq. (22) with Eq. (23). $P_{l t i}\left(V_{d}\right)$ is an LTI model where the flight velocity is fixed at $V_{d}$.

Two cases of flight control system with respect to the state feedback gain $F$ were compared in simulation. One is that $F$ was designed by GS where the plant model was $P_{\text {poly }}(V)$. Another is that $F$ was designed by LQR where the plant model was $P_{l t i}\left(V_{d}\right)$. The former is referred to as GS-SF, while the latter is referred to as Fixed-SF. The parameter values of the flight velocity profile in Fig. 3 were given as follows:

$$
\begin{aligned}
& \left(x_{r}, h_{r}\right)=(3000,0)[\mathrm{m}], \quad V_{c 1}=50, \quad V_{c 2}=15[\mathrm{~m} / \mathrm{s}] \\
& t_{c 1}=5, \quad t_{c 2}=30, \quad t_{c 3}=60, t_{c 4}=80, t_{c 5}=100[\mathrm{~s}] .
\end{aligned}
$$




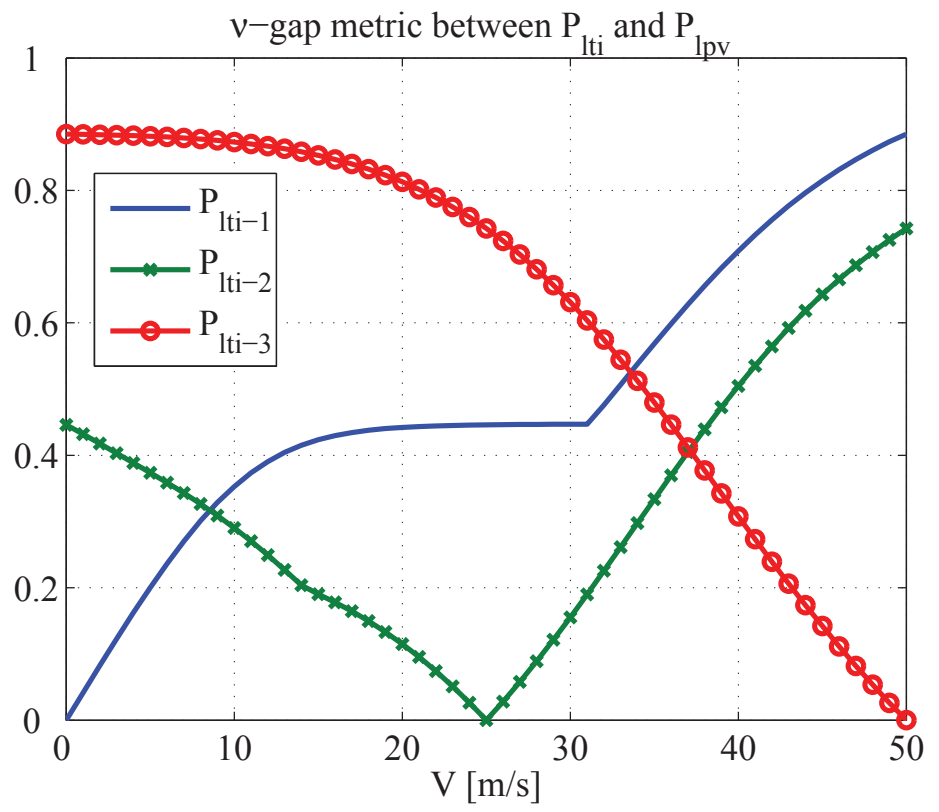

(a) LTI models

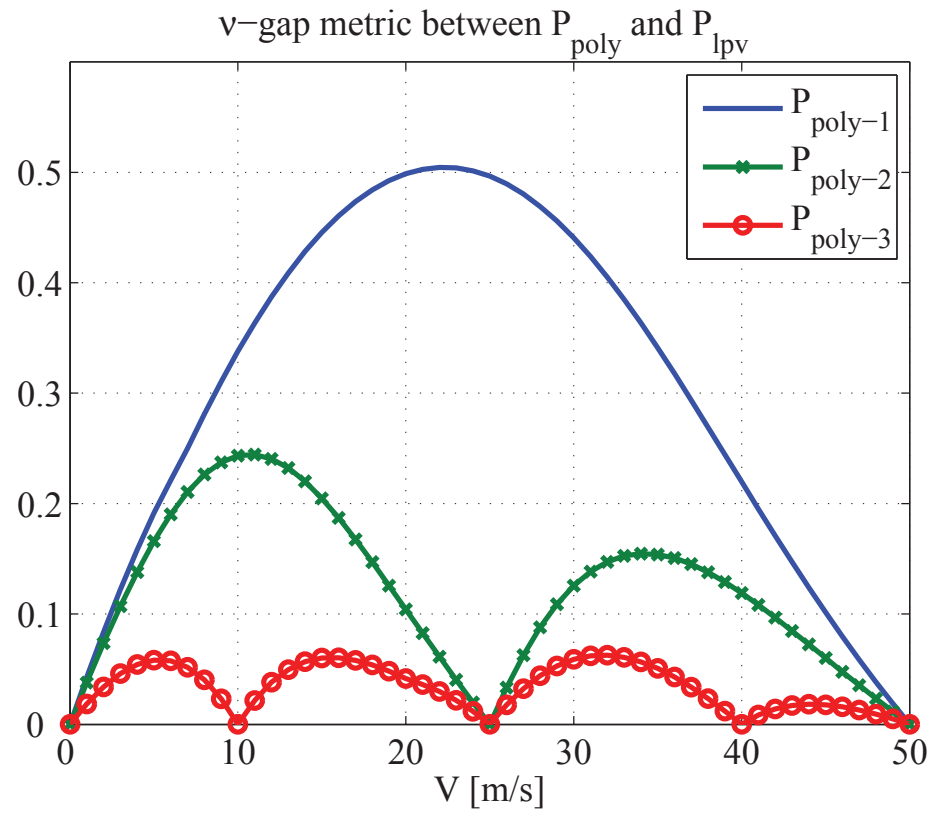

(b) polytopic models

Fig. 5. v-gap metric 


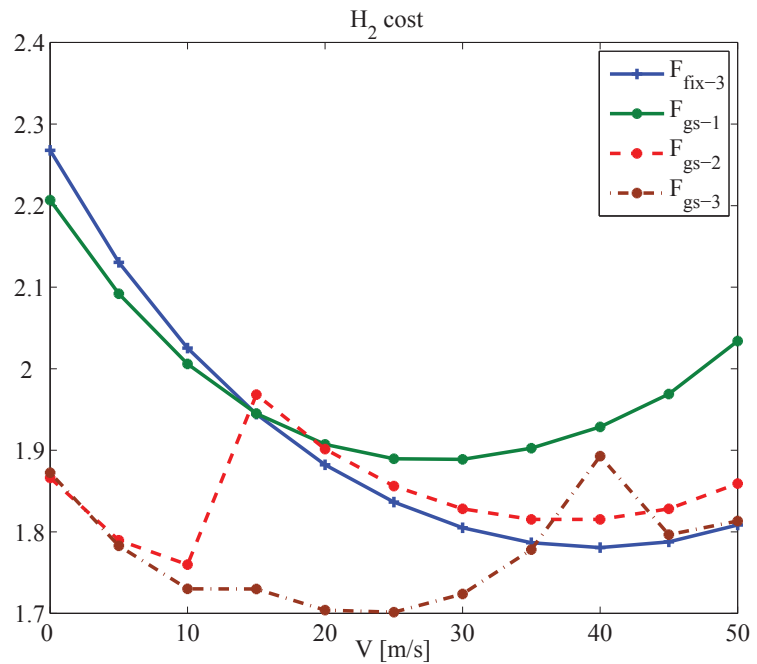

Fig. 6. $\mathcal{H}_{2}$ cost

\subsection{Evaluation of design models}

According to Section 4.1, three linear interpolative polytopic models were obtained. Table 2 shows the operating points chosen for the models. While, the design points $V_{d}$ of three LTI models are shown in Table 3. The $v$-gap metric is one of criteria measuring the model error in the frequency domain. It had been introduced in robust control theories associated with the stability margin (Vinnicombe, 2001). The $v$-gap metric between two LTI models, $P_{1}(s)$ and $P_{2}(s)$, is defined as

$$
\delta_{v}\left(P_{1}, P_{2}\right) \triangleq\left\|\left(I+P_{2} P_{2}^{*}\right)^{-1 / 2}\left(P_{1}-P_{2}\right)\left(I+P_{1} P_{1}^{*}\right)^{-1 / 2}\right\|_{\infty}
$$

The range is $\delta_{v} \in[0,1]$. A large $\delta_{v}$ means that the model error is large. The $v$-gap metric is used for evaluating the model $P_{\text {poly }}(V)$ and $P_{l t i}\left(V_{d}\right)$. Figure 5 shows $v$-gap metric between $P_{l t i}\left(V_{d}\right)$ and $P_{l p v}(V)$ and between $P_{p o l y}(V)$ and $P_{l p v}(V) . \delta_{v}\left(P_{l t i}(V), P_{l p v}\left(V_{d}\right)\right)$ was rapidly increased when $V$ was shifted from $V_{d}$. On the other hand, the maximum of $\delta_{v}\left(P_{p o l y}(V), P_{l p v}(V)\right)$ was reduced according to the number of the operating points. It was seen that $P_{\text {poly }}(V)$ appropriately approximated $P_{l p v}(V)$ over the entire range of the flight velocity.

\subsection{Design of $F$ and $\mathcal{H}_{2}$ cost}

The design parameters for designing $F$ in Eq. (30) were given as follows.

$$
B_{1}=\left[\begin{array}{cc}
-6.039 & 10.977 \\
-154.03 & 49.188 \\
3.954 & -7.187 \\
0 & 0 \\
0.38495 & -0.12395
\end{array}\right], \quad C_{1}=\left[\begin{array}{c}
0.001 I_{5} \\
0_{2 \times 5}
\end{array}\right], \quad D_{1}=\left[\begin{array}{c}
0_{5 \times 2} \\
I_{2}
\end{array}\right]
$$



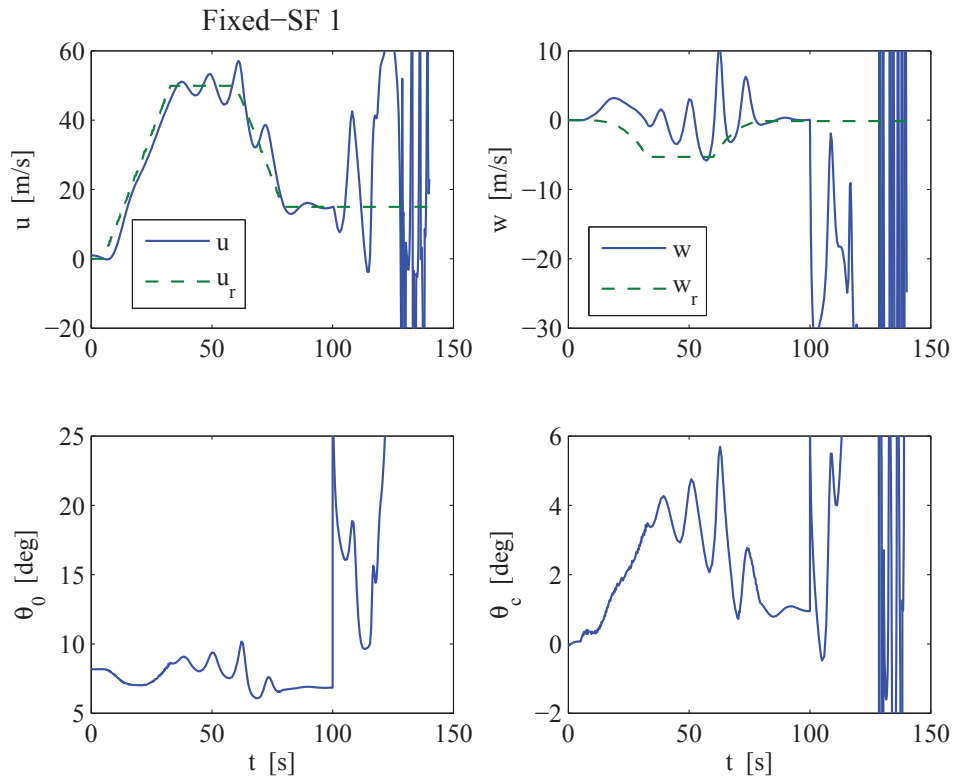

(a) Controlled variables and inputs

Fixed-SF 1
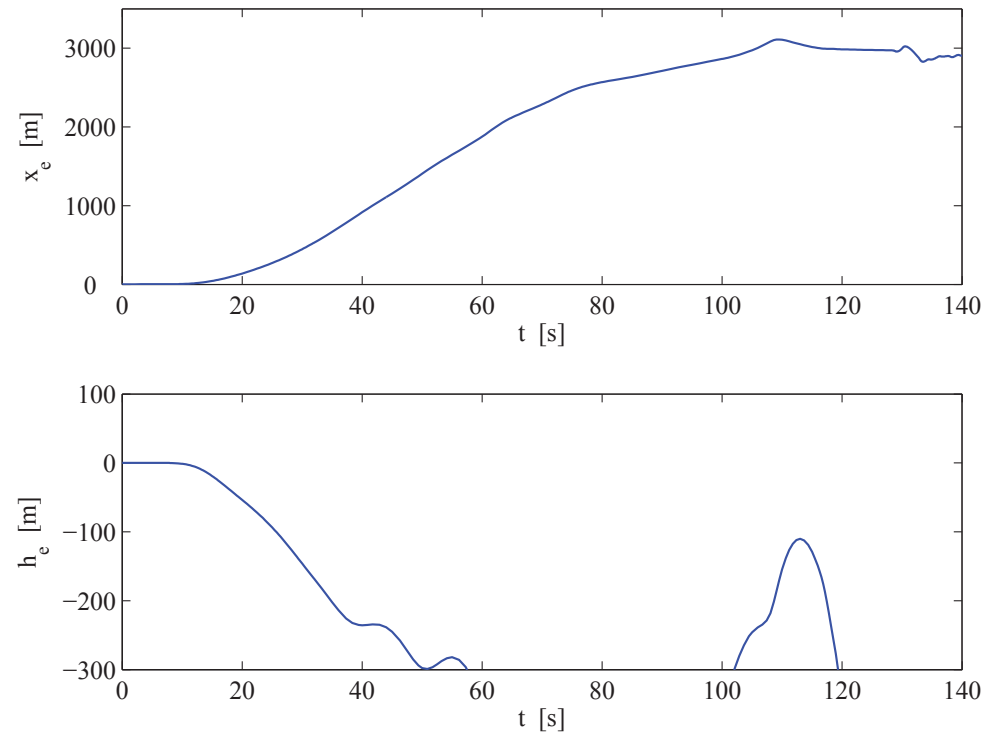

(b) Positions

Fig. 7. Time responses using $F_{f i x-1}$ 

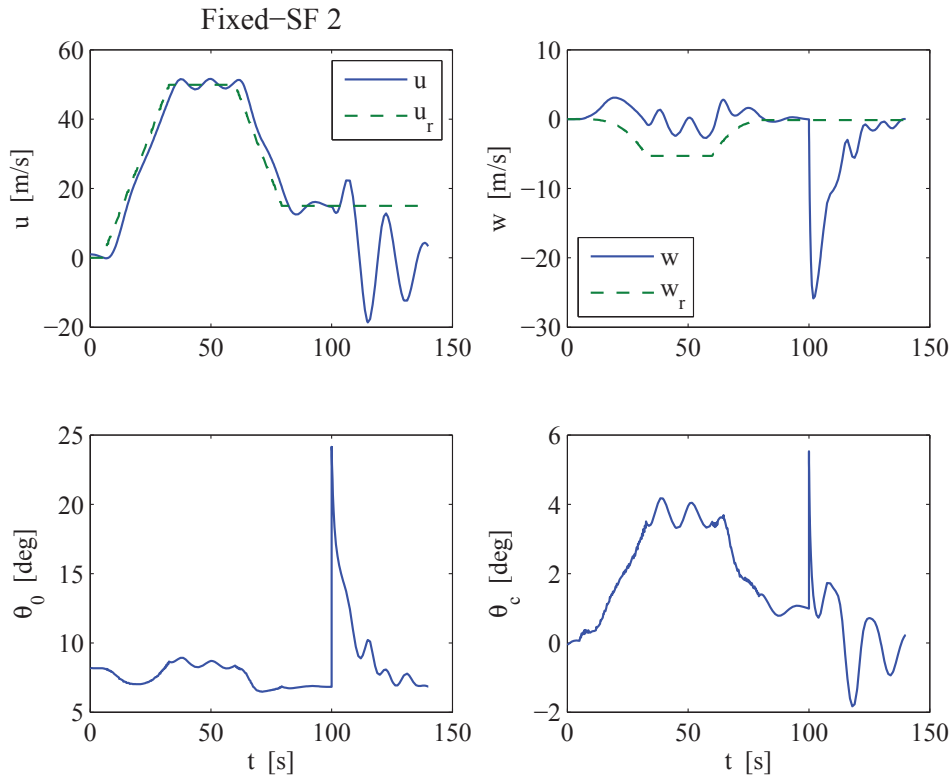

(a) Controlled variables and inputs

Fixed-SF 2
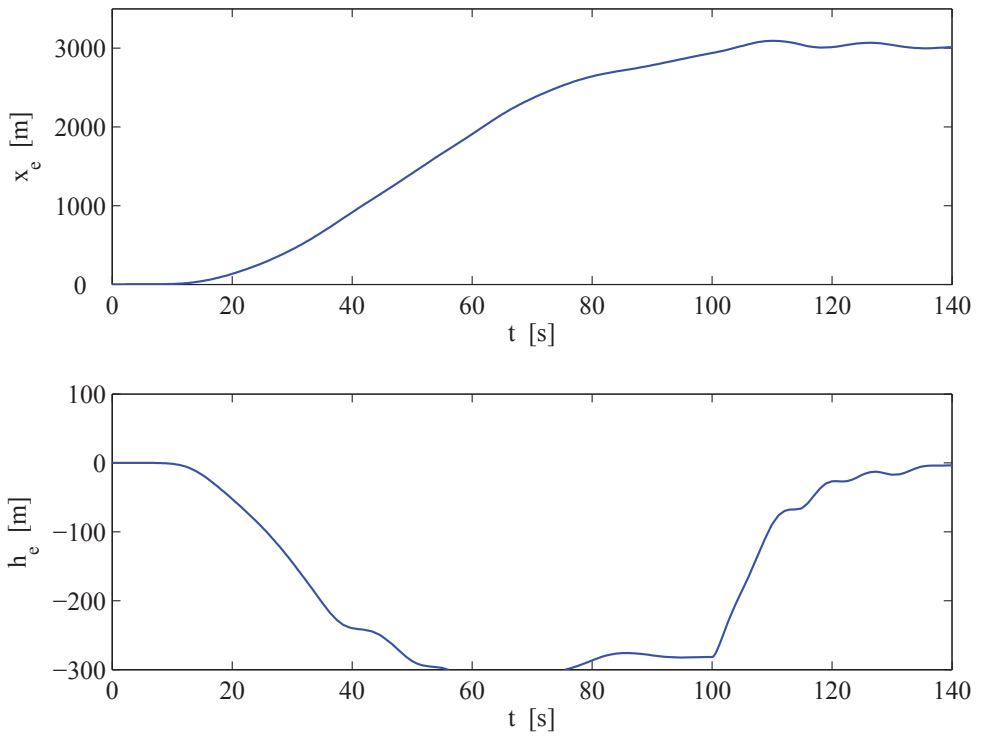

(b) Positions

Fig. 8. Time responses using $F_{f i x-2}$ 

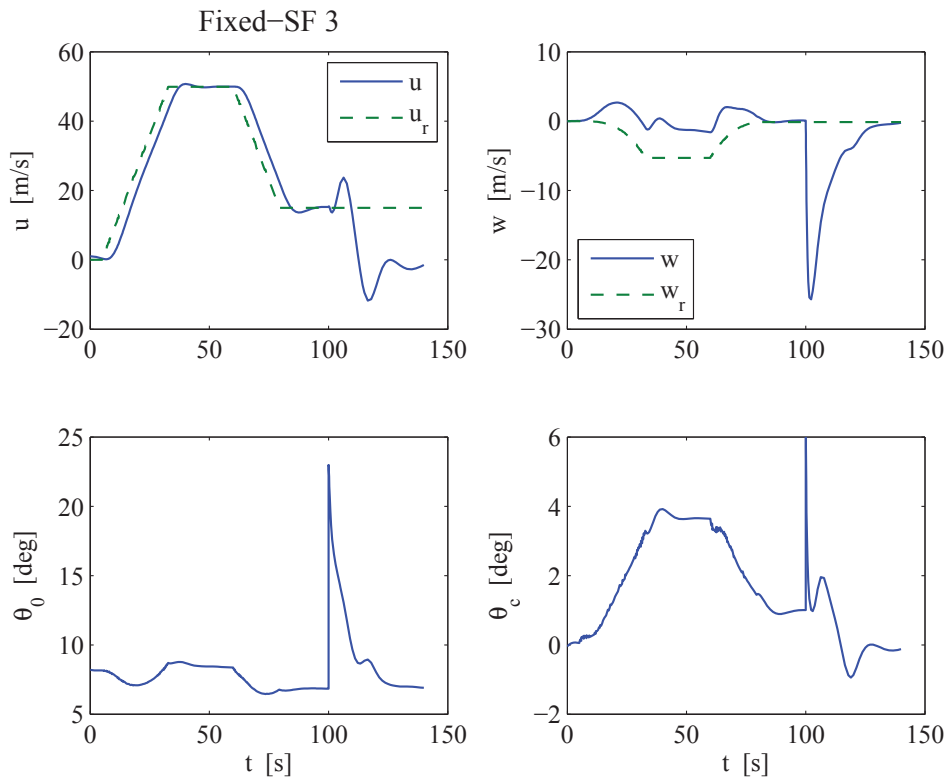

(a) Controlled variables and inputs

Fixed-SF 3
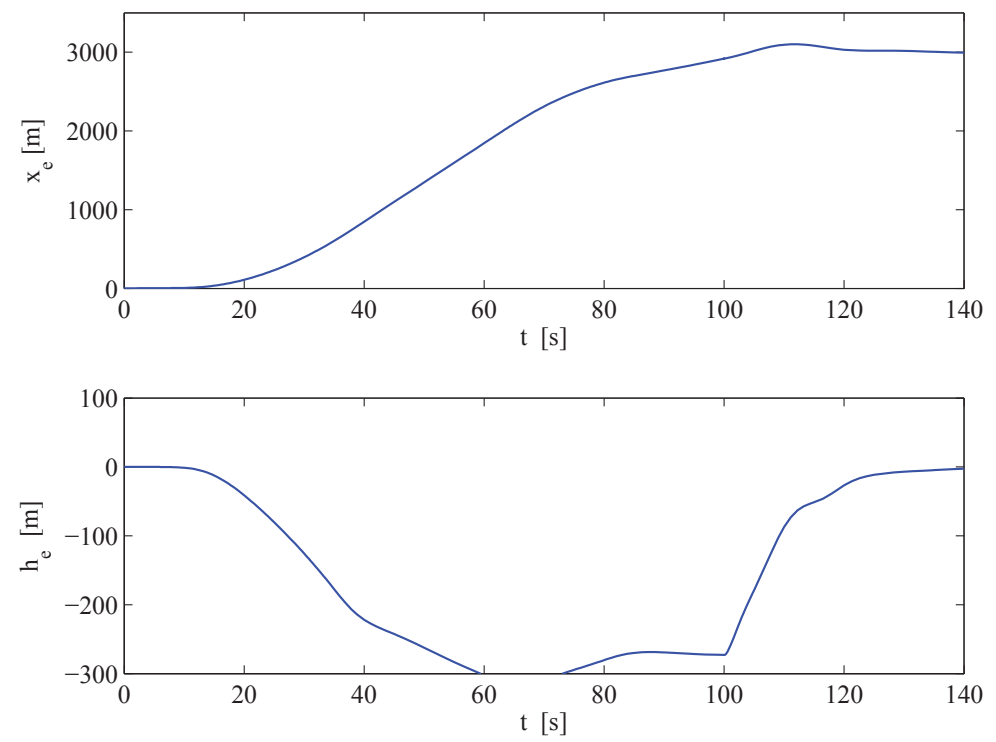

(b) Positions

Fig. 9. Time responses using $F_{f i x-3}$ 

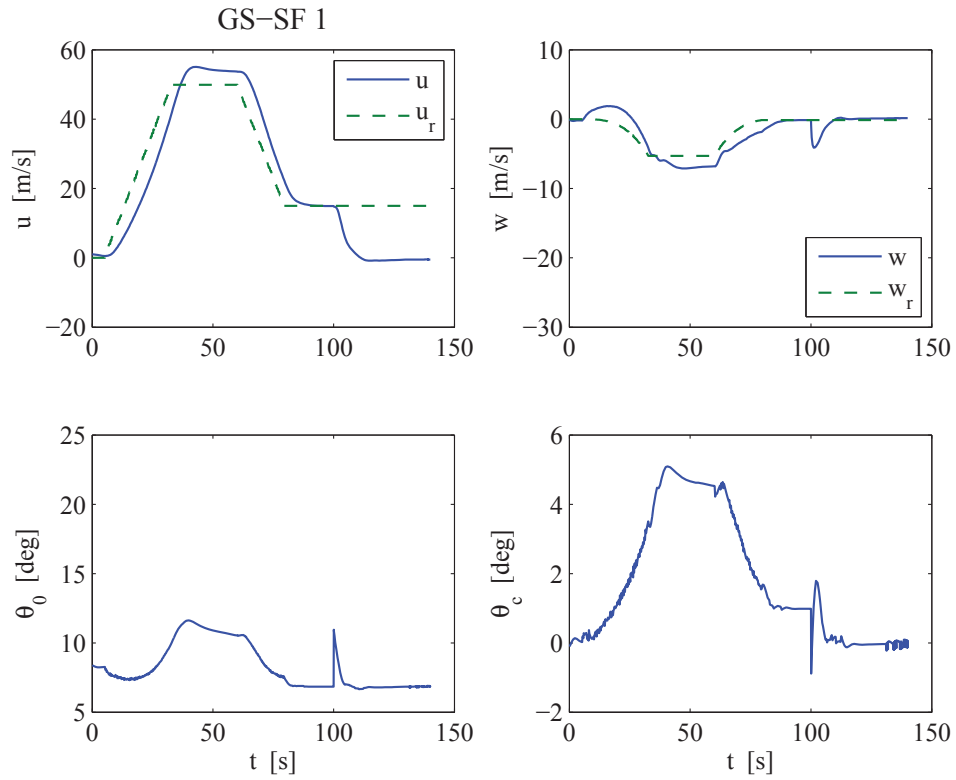

(a) Controlled variables and inputs
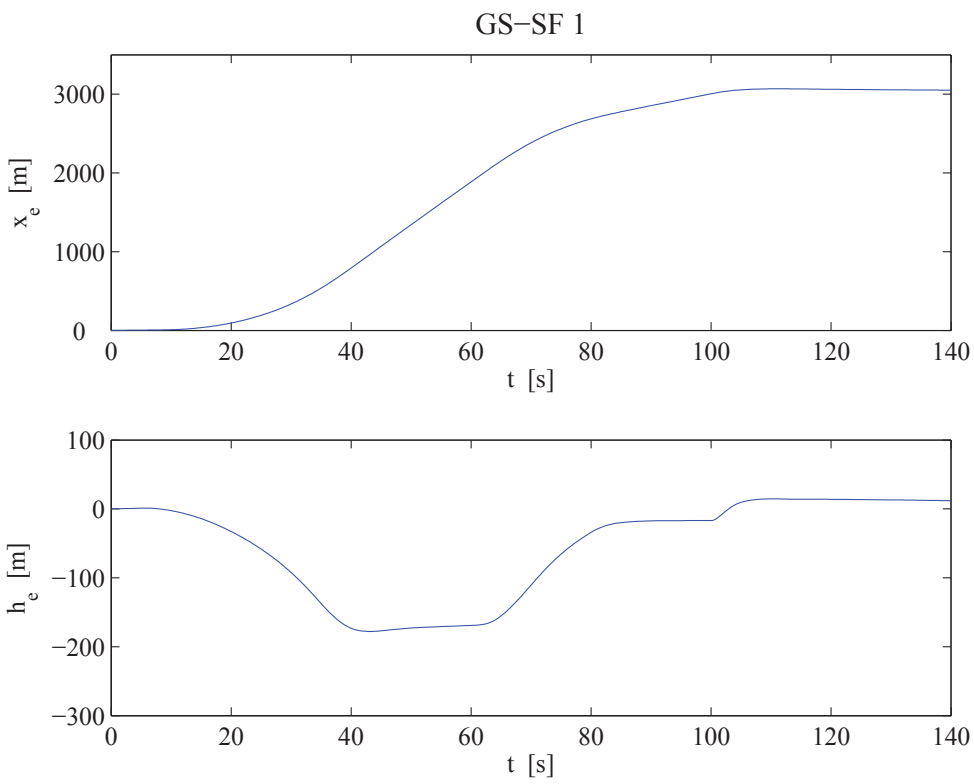

(b) Positions

Fig. 10. Time responses using $F_{g s-1}$ 

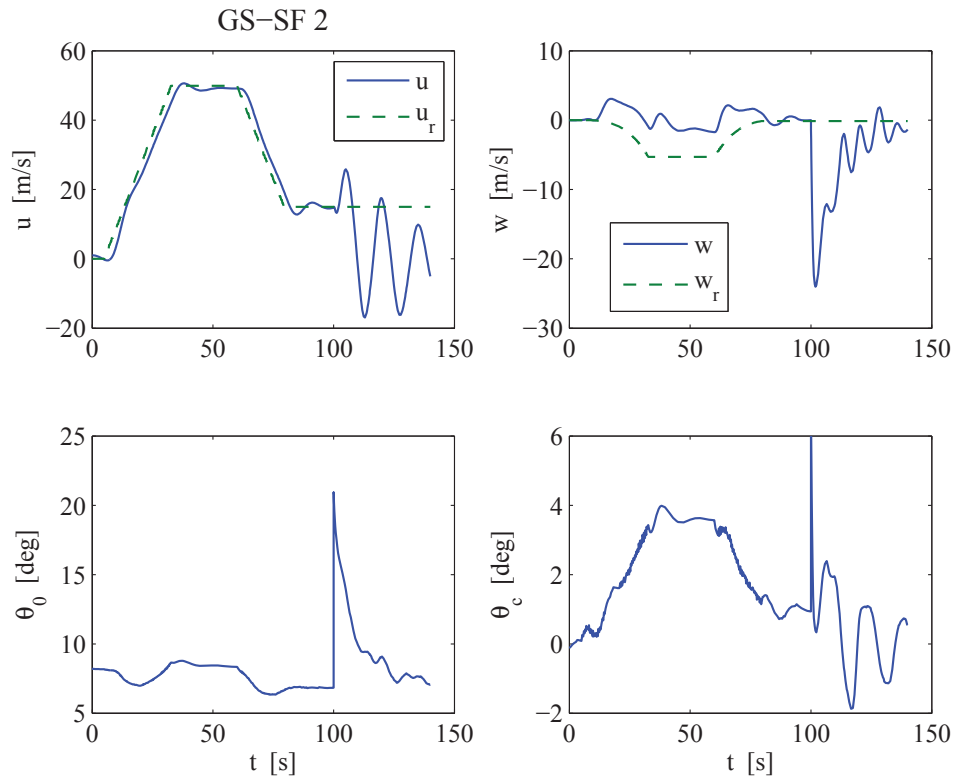

(a) Controlled variables and inputs
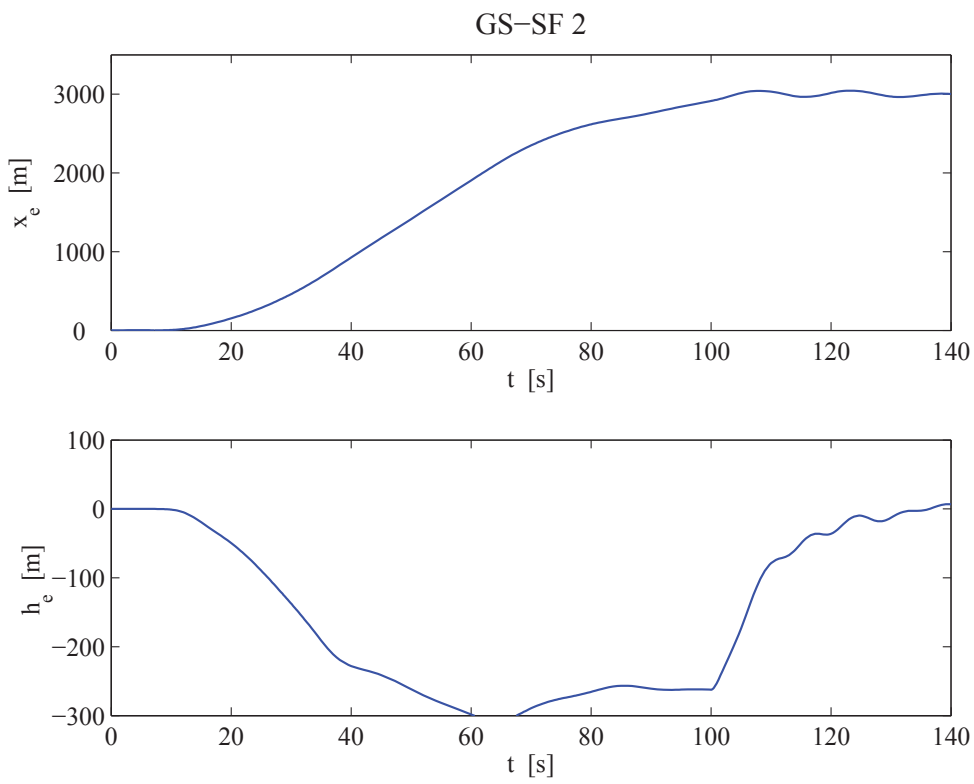

(b) Positions

Fig. 11. Time responses using $F_{g s-2}$ 

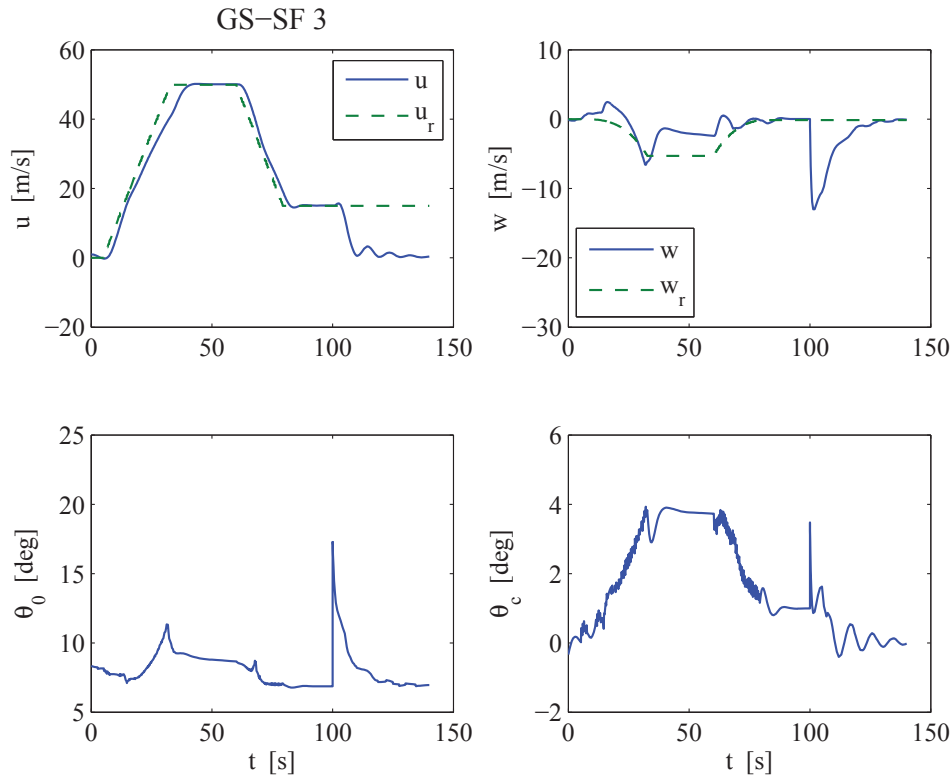

(a) Controlled variables and inputs

GS-SF 3
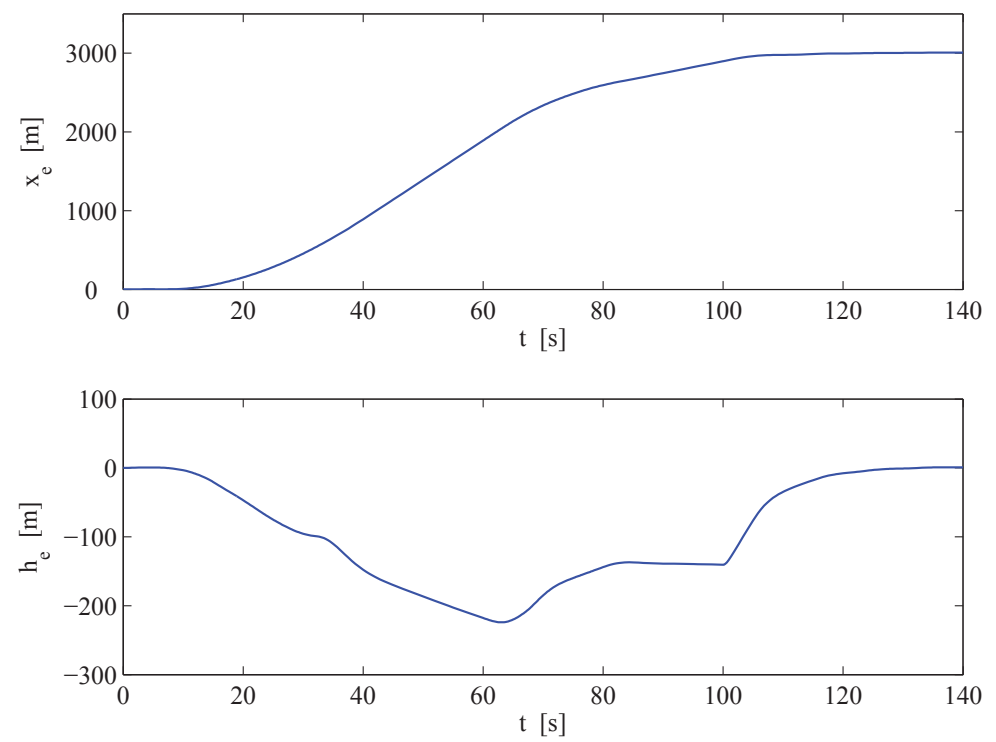

(b) Positions

Fig. 12. Time responses using $F_{g s-3}$ 
They were used for both of GS-SF and Fixed-SF. Three GS-SF gains denoted as $F_{g s-i}(i=$ $1,2,3)$ were designed according to Section 4.2 , while three Fixed-SF gains denoted as $F_{f i x-i}$ $(i=1,2,3)$ were designed by $\mathrm{LQR}$ technique in which the weights of the quadratic index were given by $C_{1}^{T} C_{1}$ and $D_{1}^{T} D_{1}$.

Figure 6 shows the $\mathcal{H}_{2}$ cost of the closed-loop system which the designed $F$ is combined with Eq. (30). The $\mathcal{H}_{2}$ cost by $F_{f i x-3}$ was minimized at $V=40[\mathrm{~m} / \mathrm{s}]$ which was near the design point $V_{d}=50[\mathrm{~m} / \mathrm{s}]$, but was increased in the low flight velocity region. The $\mathcal{H}_{2}$ cost by $F_{f i x-1}$ and $F_{f i x-2}$ showed the similar result. On the other hand, the $\mathcal{H}_{2}$ cost by $F_{g s-2}$ and $F_{g s-3}$ was kept small over the entire flight region. The $\mathcal{H}_{2}$ cost by $F_{Q S-1}$ was small in the middle flight velocity region but was increased in the low and the high flight velocity regions.

\subsection{Tracking evaluation}

The flight mission given in Fig. 3 was performed in Simulink. Figures 7 - 12 show the time histories of the closed-loop system with the three GS-SF and three Fixed-SF gains. In the case of $F_{f i x-1}$ shown in Fig. 7, the controlled variables $u$ and $w$ tracked their references until the acceleration phase $(5 \leq t<30$ [s]) but they were diverged in the cruise phase $(30 \leq t<60$ [s]). In the deceleration phase $(60 \leq t<80$ [s]), the closed-loop system was stabilized again but it was de-stabilized in the approach phase ( $t \geq 100$ [s]). Although the closed-loop system remained stable for the entire flight region in the case of $F_{f i x-2}$ shown in Fig. 8, oscillatory responses were observed in the cruise and approach phases. The responses using $F_{f i x-3}$ shown in Fig. 9 were better than those using $F_{f i x-2}$.

On the other hand, the three GS-SF gains provided stable responses as shown in Figs. 10 12, In particular, The responses by $F_{g s-3}$ showed improved tracking and settling properties compared to other cases.

Summarizing the simulation in MATLAB/Simulink, polytopic model $P_{\text {poly-3 }}$ made the $v$-gap metric smaller than other models for the entire flight region. $F_{g_{s}-3}$ designed by using $P_{p o l y-3}$ showed better control performance.

\section{Concluding remarks}

This paper has presented an autonomous flight control design for the longitudinal motion of helicopter to give insights for developing autopilot techniques of helicopter-type UAVs. The characteristics of the equation of helicopter was changed during a specified flight mission because the trim values of the equation were widely varied. In this paper, gain scheduling state feedback (GS-SF) was included in the double loop flight control system to keep the vehicle stable for the entire flight region. The effectiveness of the proposed flight control system was evaluated by computer simulation in MATLAB/Simulink. The model error of the polytopic model was smaller than that of LTI models which were obtained at specified flight velocity. Flight control systems with GS-SF showed better control performances than those with fixed-gain state feedback. The double loop flight control structure was useful for accomplishing flight mission considered in this paper.

\section{References}

[1] Boyd, S.; Ghaoui, L. E.; Feron, E. \& Balakrishnan, V. (1994). Linear Matrix Inequalities in System and Control Theory, SIAM, Vol. 15, Philadelphia.

[2] Bramwell, A. R. S. (1976). Helicopter Dynamics, Edward Arnold, London, 1976. 
[3] Cho, S.-J.; Jang, D.-S. \& Tahk, M.-L. (2005). Application of TCAS-II for Unmanned Aerial Vehicles, Proc. CD-ROM of JSASS 19th International Sessions in 43rd Aircraft Symposium, Nagoya, 2005

[4] Fujimori, A.; Kurozumi, M.; Nikiforuk, P. N. \& Gupta, M. M. (1999). A Flight Control Design of ALFLEX Using Double Loop Control System, AIAA Paper, 99-4057-CP, Guidance, Navigation and Control Conference, 1999, pp. 583-592.

[5] Fujimori, A.; Nikiforuk, P. N. \& Gupta, M. M. (2001). A Flight Control Design of a Reentry Vehicle Using Double Loop Control System with Fuzzy Gain-Scheduling, IMechE Journal of Aerospace Engineering, Vol. 215, No. G1, 2001, pp. 1-12.

[6] Fujimori, A.; Miura, K. \& Matsushita, H. (2007). Active Flutter Suppression of a High-Aspect-Ratio Aeroelastic Using Gain Scheduling, Transactions of The Japan Society for Aeronautical and Space Sciences, Vol. 55, No. 636, 2007, pp. 34-42.

[7] Johnson, E. N. \& Kannan, S. K. (2005). Adaptive Trajectory Control for Autonomous Helicopters, Journal of Guidance, Control and Dynamics, Vol. 28, No. 3, 2005, pp. 524-538.

[8] Langelaan, J. \& Rock, S. (2005). Navigation of Small UAVs Operating in Forests, Proc. CD-ROM of AIAA Guidance, Navigation, and Control Conference, San Francisco, 2005.

[9] Padfield, G. D. (1996). Helicopter Dynamics: The Theory and Application of Flying Qualities and Simulation Modeling, AIAA, Reston, 1996.

[10] Van Hoydonck, W. R. M. (2003). Report of the Helicopter Performance, Stability and Control Practical AE4-213, Faculty of Aerospace Engineering, Delft University of Technology, 2003.

[11] Vinnicombe, G. (2001). Uncertainty and Feedback ( $\mathcal{H}_{\infty}$ loop-shaping and the v-gap metric), Imperial College Press, Berlin.

[12] Wilson, J. R. (2007). UAV Worldwide Roundup 2007, Aerospace America, May, 2007, pp. 30-38. 


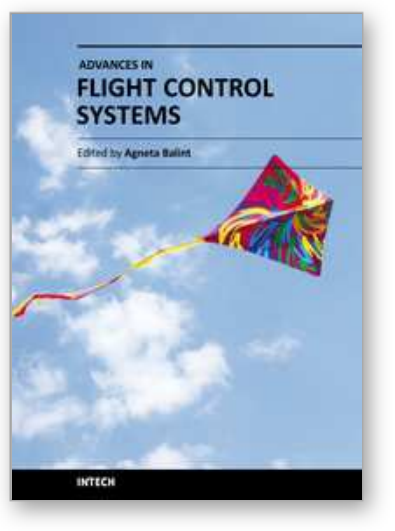

\author{
Advances in Flight Control Systems \\ Edited by Dr. Agneta Balint
}

ISBN 978-953-307-218-0

Hard cover, 296 pages

Publisher InTech

Published online 11, April, 2011

Published in print edition April, 2011

Nonlinear problems in flight control have stimulated cooperation among engineers and scientists from a range of disciplines. Developments in computer technology allowed for numerical solutions of nonlinear control problems, while industrial recognition and applications of nonlinear mathematical models in solving technological problems is increasing. The aim of the book Advances in Flight Control Systems is to bring together reputable researchers from different countries in order to provide a comprehensive coverage of advanced and modern topics in flight control not yet reflected by other books. This product comprises 14 contributions submitted by 38 authors from 11 different countries and areas. It covers most of the currents main streams of flight control researches, ranging from adaptive flight control mechanism, fault tolerant flight control, acceleration based flight control, helicopter flight control, comparison of flight control systems and fundamentals. According to these themes the contributions are grouped in six categories, corresponding to six parts of the book.

\title{
How to reference
}

In order to correctly reference this scholarly work, feel free to copy and paste the following:

Atsushi Fujimori (2011). Autonomous Flight Control System for Longitudinal Motion of a Helicopter, Advances in Flight Control Systems, Dr. Agneta Balint (Ed.), ISBN: 978-953-307-218-0, InTech, Available from: http://www.intechopen.com/books/advances-in-flight-control-systems/autonomous-flight-control-system-forlongitudinal-motion-of-a-helicopter

\section{INTECH}

open science | open minds

\section{InTech Europe}

University Campus STeP Ri

Slavka Krautzeka 83/A

51000 Rijeka, Croatia

Phone: +385 (51) 770447

Fax: +385 (51) 686166

www.intechopen.com

\section{InTech China}

Unit 405, Office Block, Hotel Equatorial Shanghai

No.65, Yan An Road (West), Shanghai, 200040, China

中国上海市延安西路 65 号上海国际贵都大饭店办公楼 405 单元

Phone: +86-21-62489820

Fax: $+86-21-62489821$ 
(C) 2011 The Author(s). Licensee IntechOpen. This chapter is distributed under the terms of the Creative Commons Attribution-NonCommercialShareAlike-3.0 License, which permits use, distribution and reproduction for non-commercial purposes, provided the original is properly cited and derivative works building on this content are distributed under the same license. 